\title{
Através do Espelho: o acontecimento Isabella na revista Veja ${ }^{1}$ Through the looking-glass: Isabella's event in Veja newsmagazine
}

Paulo Bernardo Ferreira Vaz I paulobvaz@gmail.com Professor do Programa de Pós-Graduação em Comunicação Social da UFMG; doutor em Comunicação e Educação pela Université de Paris XIl; mestre em Editoração e Audiovisual; pesquisador associado do CNPq.

Renné Oliveira França I renneof@gmail.com Doutorando do Programa de Pós-Graduação em Comunicação Social da UFMG, mestre em Comunicação Social pela UFMG; bolsista da CAPES; professor substituto do Departamento de Comunicação Social da UFMG.

\section{Resumo}

O artigo busca perceber os movimentos elaborados na tentativa de construçáo de sentido frente a um acontecimento. Para tal, partimos das indagaçôes do filósofo Gilles Deleuze e do sociólogo Louis Quéré sobre a natureza paradoxal do acontecimento, especialmente em sua relação com a linguagem, buscando relacioná-lo ao fazer jornalístico a partir da cobertura da revista Veja no caso Isabella Nardoni.

Palavras-chave: acontecimento, linguagem, jornalismo, sentido, revista.

\begin{abstract}
The paper aims to understand the tries of construction of the sense in an event. To this end, we assume questions of the philosopher Gilles Deleuze and the sociologist Louis Quere about the paradoxical nature of the event, especially in its relationship with the language, seeking to relate it to the journalist work according the coverage of magazine Veja in Isabella Nardoni case.
\end{abstract}

Keywords: event, language, journalism, sense, magazine. 


\section{A MENINA NO ESPELHO}

“Oh, Kitty, que bom seria atravessar para dentro da Casa do Espelho! Tenho certeza de que existem coisas lindas lá dentro. Vamos fazer de conta que existe uma maneira de atravessar, Kitty”.

Lewis Carroll. Através do Espelho e o que Alice encontrou lá.

Alice atravessa o espelho e se encontra na mesma sala em que estava antes, só que lá está tudo ao contrário. Nesse mundo através do espelho todas as coisas são ao contrário. Quanto mais perto, mais longe ficamos do que está sendo refletido, a não ser de nossa própria imagem; assim, para se aproximar da rainha, Alice deve se afastar dela.

As Aventuras de Alice no País das Maravilhas e Através do Espelho e o que Alice encontrou lá, de Lewis Carroll, são obras fundamentais para Gilles Deleuze explicar o conceito de acontecimento e a noção de produção de sentido no seu Lógica do Sentido. A personagem título está sempre frente a situaçóes paradoxais, acontecimentais em sua falta de sentido, instalando campos problemáticos aparentemente impossíveis de serem resolvidos. $\mathrm{O}$ universo fantástico de Alice nos dá a ver o poder de significação de um acontecimento, coloca-nos frente a situaçóes tão absurdas que fogem do esperado, quebrando as expectativas. A lógica necessária para se mover através do espelho é oposta àquela que estamos acostumados. Essa poderia ser também a lógica do acontecimento. Quanto mais nos afastamos de seu "núcleo"2 - fato inicial que provoca seu desencadeamento -, mais próximos ficamos de seu sentido.

Procuramos olhar, neste trabalho, para outra criança que se desloca para o centro do acontecimento. Aqui não se verá mais Alice e seu mundo de fantasias, mas Isabella e sua trágica realidade. A proposta é olhar para um acontecimento que conseguiu afetar todo um país: no sábado do dia 29 de março de 2008, após as 23h, a menina Isabella Oliveira Nardoni, de cinco anos de idade, foi assassinada, jogada pela janela de seu apartamento no sexto andar de um edifício de classe média alta na cidade de São Paulo. Filha de Ana Carolina Oliveira e Alexandre Nardoni, a menina passava a noite com o pai e a madrasta Anna Carolina Jatobá, junto a seus dois meio-irmáos. O corpo da menina apresentava sinais de asfixia sofrida antes da queda, o que imediatamente fez surgir a suspeita de que ela tenha sido jogada pela janela na tentativa de acobertar um assassinato por agressão.

O que se viu a partir daí foi uma avalanche de material informativo se avolumando e despencando por horas, dias, semanas seguidas sobre telespectadores, leitores, ouvintes e usuários da internet. Capas de jornais e revistas, transmissôes de rádio, entradas ao vivo de emissoras de televisão e matérias atualizadas em sites informativos, tudo isso mobilizava não só a atenção de sujeitos em contato direto com as informaçóes, mas também de multidóes que se postavam à frente da casa dos suspeitos e da delegacia, procurando se posicionar na zona de foco do acontecimento. O sorriso da desconhecida Isabella 
tornou-se onipresente. Surgiram suposiçôes e discursos autorizados de especialistas, falas indignadas, compondo uma verdadeira comoção nacional.

Interessamos, neste trabalho, em averiguar este acontecimento que reverberou com força e produziu sentido. Dentre tantos relatos, nossa escolha recaiu sobre Veja, que destacou o caso em duas matérias de capa no mês de abril de 2008. Como é próprio do jornalismo, a revista buscou dar significaçáo ao acontecimento e organizá-lo. Mas intrigou-nos a questão que tentamos responder: como dar sentido àquilo que é por natureza paradoxal? A partir da conceituação de Deleuze sobre as proposiçóes e sua relação com o sentido que é expresso, este acontecimento pretende ser observado em movimento. $\mathrm{O}$ olhar recai sobre as ondas que reverberam nessas duas ediçóes da revista. Quanto mais se afastam da fatídica noite de 29 de março, mais essas ondas se voltam para o fechamento de um sentido que explica o que aconteceu. Quanto mais se afasta de seu "núcleo", mais o acontecimento volta para seu início. Ao se afastar do fato que originou o acontecimento, Veja se aproxima do acontecimento como fato. Mais distante é mais próximo. Assim como Alice através do espelho.

\section{ACONTECIMENTO}

O acontecimento não é compreensível em um primeiro momento, uma vez que é rompida a serialidade daquilo que decorre e configura o possível. Segundo Quéré, "não se compreende o acontecimento porque não podemos ainda inseri-lo num contexto, nem considerá-lo como resultado de um encadeamento serial” (QUÉRÉ, 2005, p. 07). Ao acontecer, somos obrigados a reconhecer possibilidades que julgávamos impossíveis, que excediam nosso sentido do provável. O possível está relacionado com o momento presente da experiência do sujeito: náo se pode definir uma possibilidade sem levar em conta o agora, "momento singular e contingente a partir do qual se abrem possíveis" (QUÉRÉ, 2005, p. 09). O corte na continuidade provoca a possibilidade de novos possíveis serem configurados.

O acontecimento liga-se diretamente à idéia de provável, funcionando como força que rompe com as expectativas, efetuando-se sobre o sujeito, que é incapaz de uma contra-afetação, pois não há sentido na ação que se dá. Para Deleuze (1982), o acontecimento é paradoxal, da ordem da impropriedade: contraria o bom senso que fecha o sentido, assim como o senso comum que fixa identidades. Nesse local de troca entre o estado de coisas e o improvável, o sujeito busca produzir algum tipo de sentido pela contra-efetuação. E exatamente por náo ter sentido em meio àquilo que já existe, o acontecimento faz com que o sujeito busque novos significados para dar conta do que acontece a ele. Deleuze identifica o sentido à expressão: é através dela que se dá a significação, produzida pelo sujeito em meio à sua afetação pelo paradoxal. "O acontecimento pertence essencialmente à linguagem, ele mantém uma relação essencial com a linguagem; mas a linguagem é o que se diz das coisas" (DELEUZE, 1982, p. 23). A expressão se dá através da linguagem, que busca organizar o improvável, fechando seu sentido. Se o sentido é o expresso, 
podemos compreender o local de sua produção como algo entre o estado de coisas que é abalado e a linguagem. O sentido é o próprio acontecimento expresso; é aquilo que se produz pelo rompimento do bom senso e do senso comum, obrigando a uma nova significação do possível: o acontecimento abre-se à história, sugando tudo ao seu redor.

O campo problemático aberto pelo acontecimento exige essa investigação que vai levar ao sentido produzido. Ele passa entáo a ser organizado em forma de intriga, de modo a apaziguar o paradoxo, retirando seu poder através do movimento dos sujeitos de reorganizar suas experiências afetadas. $\mathrm{O}$ sujeito faz uso de suas experiências passadas para organizar o acontecimento através de uma relação de causa e efeito que não dá conta do acontecimento, já que ele envolve uma relação temporal diferente, que traz para si uma simultaneidade de tempos para a produção de sentido. Dessa maneira, o acontecimento deve ser pensado como uma complexa cadeia temporal formada pela contra-efetuação do sujeito, que ao ser atingido busca outras experiências para amenizar o paradoxo.

Funcionando como uma onda com grande poder de afetação, o acontecimento se propaga graças à série de sentidos atribuídos ao seu paradoxo, que vão se inserindo pelas várias mediaçóes encontradas pelo caminho. A mídia funciona como um desses locais de ordenaçáo do acontecimento, contribuindo para o sentido que se produz. Mas entre o acontecimento e sua expressão pela linguagem, há enunciados que se apresentam, segundo Deleuze, em relaçóes distintas na proposição. O autor propóe três relaçóes claras - designação ou indicação, manifestação e significação - e uma quarta onde se dá o sentido: expressão. Essas relações na proposição não se dão de maneira hierárquica ou causal, mas formando uma unidade sistemática de onde deriva o sentido.

\section{Designação ou indicação}

A designação ou indicação é a relação da proposição a um estado de coisas exteriores (DELEUZE, 1982, p. 13). O estado de coisas comporta diferentes corpos e relaçóes, e a designação atua exatamente pela associação das palavras a imagens particulares "colhidas" em meio à complexificação do estado de coisas com o objetivo de representá-lo como um todo. "O que conta, no momento, é que certas palavras na proposição, certas partículas lingüísticas, servem como formas vazias para a seleçáo das imagens em todo e qualquer caso..." (DELEUZE, 1982, p. 13).

Frente a um acontecimento, nosso movimento de designação passa por essa tentativa de buscar particularidades para definir o estado de coisas que foi "quebrado" por esse acontecimento. O jornalismo, em sua busca por ordenação da realidade, faz escolhas dentro dos vários corpos e relaçóes para representar aquilo que aconteceu e disponibilizá-lo para o público a partir de uma aproximação daquilo que Deleuze apresenta como indicadores formais: "Estes indicadores são: isto, aquilo; ele; acolá; ontem, agora etc. Os nomes próprios também são indicadores ou designantes, mas de uma importância especial porque são os únicos a formar singularidades propriamente materiais" 
(DELEUZE, 1982, p. 13).

O acontecimento Isabella apresentado pela revista Veja do dia 09 de abril de 2008 se dá pela designação dos envolvidos na história, como a própria vítima e os suspeitos: o pai Alexandre Nardoni e a madrasta Anna Carolina Jatobá. A designação se dá não apenas pelas palavras, mas também pelas imagens. Acima da manchete "O ANJO E O/ MONSTRO" (pág. 96), a revista apresenta uma fotografia da vítima.

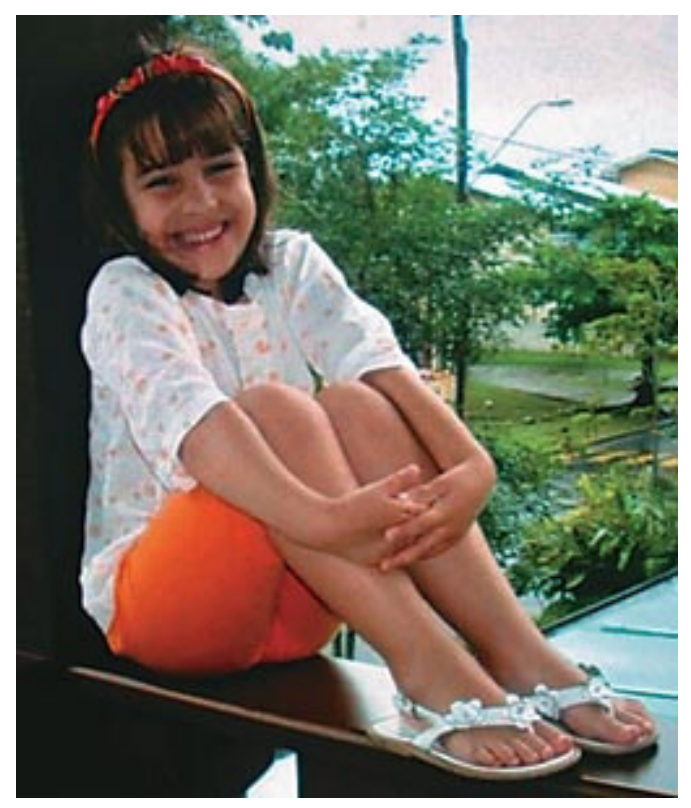

A palavra "anjo" designa claramente a menina, além de trazer referências à bondade, beleza, pureza e inocência. A imagem de Isabella deixa mais clara essa designação, sentada em um parapeito de varanda, com as mãos entrelaçadas sobre as pernas dobradas junto ao corpo, com um bonito jardim ao fundo. A imagem não traz nenhuma informação jornalística, a não ser a designação clara de que foi esta criança, tão bonita, com seu sorriso inocente, que morreu de maneira bárbara, jogada pela janela. Além da imagem de Isabella, duas outras fotos ilustram as duas páginas da reportagem. Assim como "anjo" é associado à menina, "monstro" inevitavelmente designa um dos parceiros retratados nas fotos ao lado. 


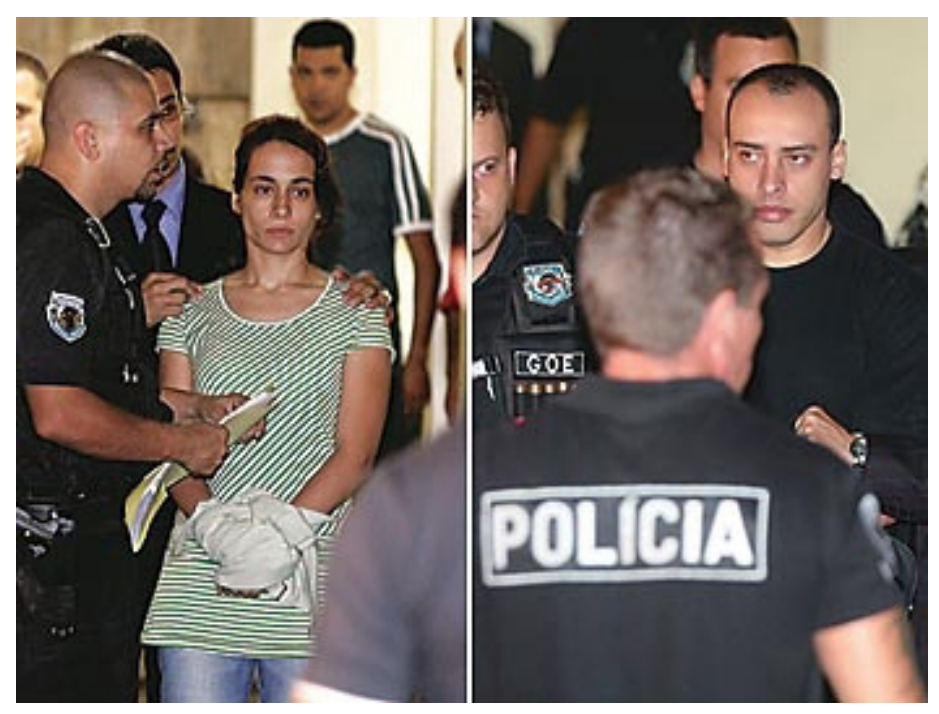

Abaixo a legenda: "Os suspeitos. Anna Carolina Jatobá e Alexandre Nardoni, madrasta e pai de Isabella, no momento da prisão. Em carta divulgada pouco antes, ele disse ter prometido junto ao caixão da filha que não vai sossegar enquanto não 'encontrar o monstro' que a matou”. A designação do substantivo "monstro" é ambígua: tanto traz referências de mal absoluto, quanto designa o suposto assassino da menina (fala do pai), além de se referir ao casal que aparece nas fotos ostentosamente cercado pela polícia.

Pela designação, a revista apresenta os envolvidos no acontecimento (imagem, idade, profissão, história), o local do crime (Guarulhos, SP) e as suspeitas da polícia (casal Nardoni-Jatobá). Mas a ausência de sentido no assassinato da garota impede uma designação a significados claramente diretos, obrigando à revista uma significaçáo particular para o acontecimento.

\section{Manifestação}

Segundo Deleuze, a manifestação trata da relação da proposição ao sujeito que fala e se exprime. "A manifestação se apresenta, pois, como o enunciado dos desejos e das crenças que correspondem à proposição" (DELEUZE, 1983, p. 14). Imagens e textos apresentam-se como enunciado do estado de coisas correspondente: no lançamento desta edição de Veja não havia motivos nem sentidos no crime, dificultando o processo de designação da revista. Enquanto designa os personagens envolvidos no acontecimento, Veja não possui referentes ao assassinato cometido. Para passar da designação à manifestação, foi feito um deslocamento de valores onde a causa não é associada a um personagem real, e sim, a um "Mal" generalizado. No acontecimento Isabella, Veja fundamenta seu juízo de designação em sua capa da edição de 09 de abril de 2008. 


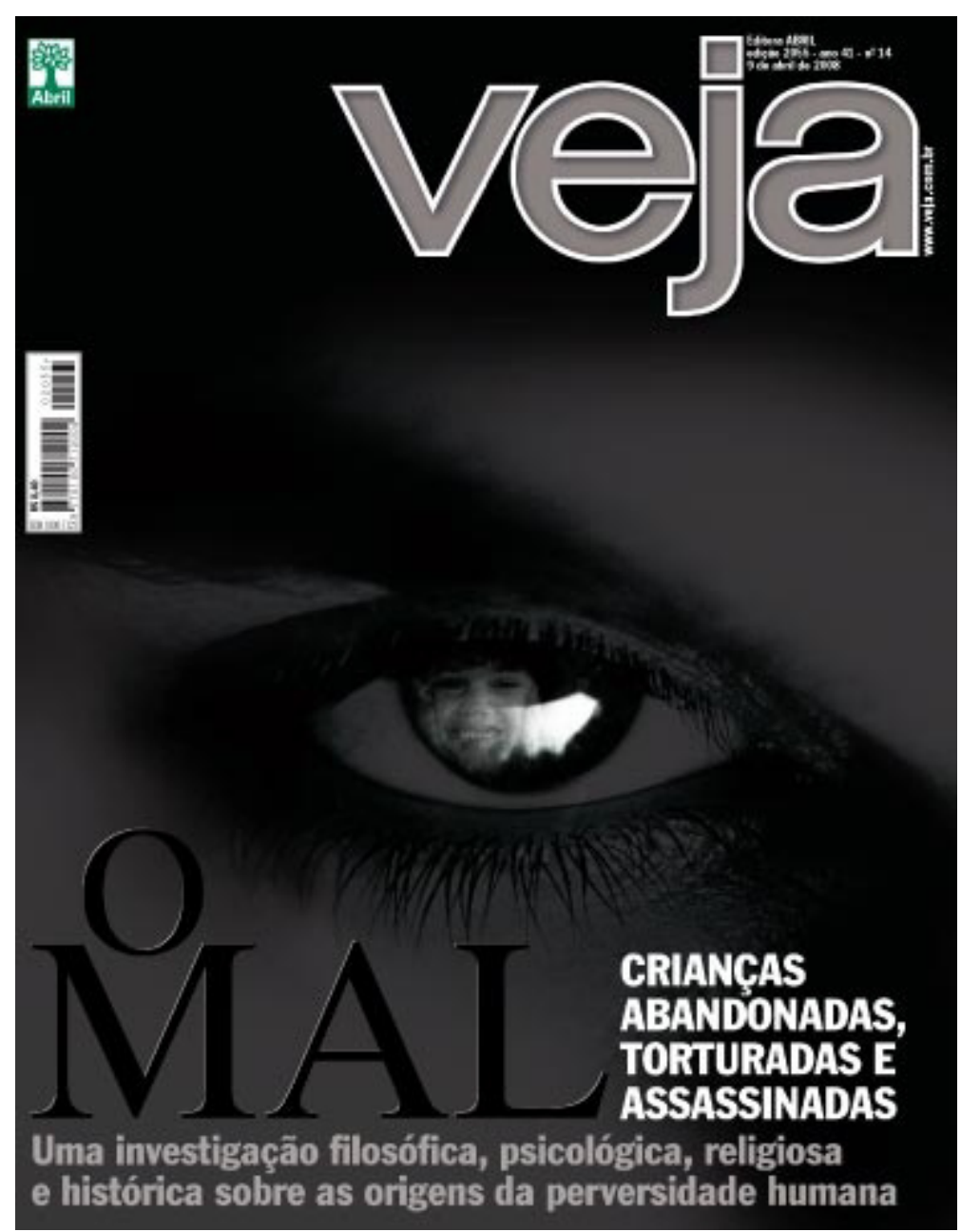

A capa trouxe a imagem de um grande olho, em cuja íris aparece refletido o rosto da menina Isabella sorrindo. Em tons bastante escuros - preto e grafite, o que no impresso dificulta o reconhecimento do olho em close-up -, a capa faz uso de palavras mais generalistas em sua designaçáo inicial do acontecimento. "O/MAL" em manchete sugere e generaliza um culpado para um caso que ainda não fecha o sentido. O choque inicial da morte da criança ainda é paradoxal, impedindo uma construção de intriga pela ordem causal, própria do jornalismo. A manifestação do acontecimento aparece, então, diretamente relacionada às escolhas de Veja: enquanto a designação buscava escolhas específicas com clara designação (menina, pai e madrasta possuem um nome próprio e imagens próprias), a manifestação constitui um domínio pessoal daquele que faz o enunciado. Manifestar o acontecimento por uma designação do mal é uma escolha deliberada de Veja, não só por se tratar de uma reportagem de capa, mas por dedicar seis páginas do miolo discutindo a maldade. A reportagem específica do caso Isabella, "O ANJO E O/MONSTRO”, ocupa apenas duas páginas. A falta de informaçóes e sentido na morte da menina obriga a ênfase dessa edição à maldade como explicação para aquilo que, segundo a revista "não tem explicação". Ou não tem sentido.

O caráter paradoxal do acontecimento fica claro nessa designação inicial que abre a matéria da página 89: "A morte de uma menina de 5 anos 
aparentemente jogada da janela do $6^{\circ}$ andar já seria por si só brutal - mas o caso é tanto mais chocante porque o pai da garotinha aparece como suspeito do crime". A ausência de sentido impede uma designação clara do estado de coisas e obriga a revista a buscar relações históricas arbitrárias, em uma tentativa de forçar uma relação de causa e efeito que não é ainda possível, dada a força do acontecimento.

A página dupla que abre a reportagem "QUANDO/O MAL/TRIUNFA", é dominada por uma montagem fotográfica com o uso de retículas exageradamente ampliadas para evidenciar o uso de fotos publicadas em jornais. Com este artifício gráfico, Veja aproxima Isabella de outros acontecimentos bastante conhecidos: inglesinha desaparecida; iraquiano torturado em Abu Ghraib; garota maltratada em Goiânia; menina assassinada em São Paulo; crianças mortas pelo terrorismo na Rússia.

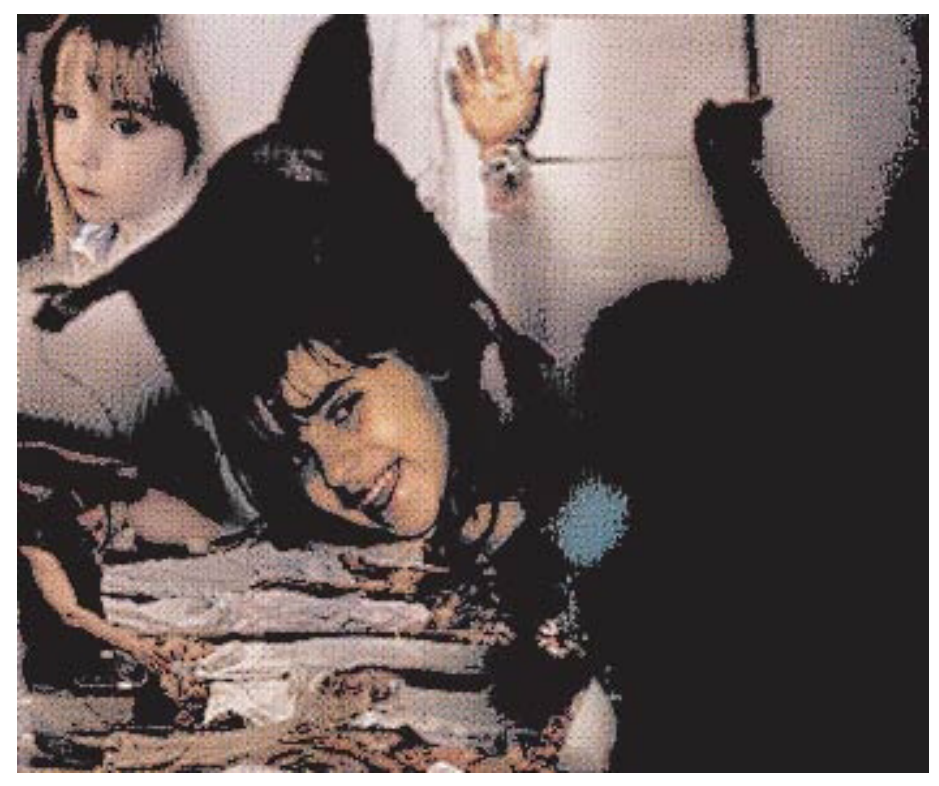

O acúmulo de diferentes referências para designar o acontecido demonstra a dificuldade de lidar com algo que ainda não há como significar. A revista associa a morte de Isabella tanto de maneira óbvia - como o desaparecimento da criança Madeleine, cujos pais também são suspeitos - até casos mais distantes - como a tortura dos prisioneiros iraquianos. Sem explicação para a morte da menina, a reportagem busca uma explicação em um mal geral, intrínseco ao ser humano e que responde por vários atos bárbaros. Com essas referências Veja procura reverberar o acontecimento e aumentar a força de propagação das ondas.

\section{Significação}

Como foi dito anteriormente, designação, manifestação e significação não surgem em separado, mas se relacionam o tempo todo na produção de sentido. Deleuze define significação como a relação da palavra com conceitos universais ou gerais. "A significação se define por esta ordem de implicação 
conceitual em que a proposição considerada não intervém senão como elemento de uma 'demonstraçáo', no sentido mais geral da palavra, seja como premissa, seja como conclusão” (DELEUZE, 1982, p. 15).

A significação está sempre em relação com as outras proposições das quais se conclui, ou cujas conclusões ela torna possível. Enquanto a designação se refere ao procedimento direto, a significação se refere a um procedimento indireto, em que o valor náo é mais a verdade, mas as condiçóes de verdade, que segundo Deleuze seriam o conjunto das condiçóes sobre as quais uma proposição seria verdadeira.

A falta de sentido do acontecimento Isabella se dá pela sua falta de significação, e a revista faz um trabalho de buscar significado para aquilo que não possui sentido. O absurdo é explicado por uma significação construída em cima da referência ao conceito de maldade. Outro exemplo dessa passagem do acontecimento da designação à significação, pode ser visto em um quadro que se prolonga ao pé das três páginas da reportagem de capa. Sob o título "Um enigma profundo", o box apresenta o mal na religiáo (serpente do Éden), o mal na natureza (terremoto de Lisboa de 1755) e o mal do homem. Mais uma vez vemos relaçôes diversas na busca por um significado.

Deleuze explica o círculo da proposição como essas relaçôes complexas que se dão entre designação, manifestação e significação na produção de sentido. A morte de Isabella possui uma designação direta bastante clara: trata-se de uma menina assassinada aos cinco anos de idade, com características físicas próprias. A designação faz referências a dados verdadeiros e indiscutíveis, mas não é local de produção de sentido. A designação só tem sentido em relação ao Eu que se manifesta.

Da relação entre as escolhas da revista da maneira como a designação se manifesta surge a significação daquilo que a princípio não tem significado: o mal é a causa da morte da menina. A noção de maldade é recuperada para significar o acontecimento, e o mal passa a explicar uma série de outros acontecimentos isolados do caso Isabella.

\section{O sentido}

Deleuze aponta o sentido como a quarta dimensão da proposição. "Os Estóicos a descobriram com o acontecimento: o sentido é o expresso da proposição, este incorporal na superfície das coisas, entidade complexa irredutível, acontecimento puro que insiste ou subsiste na proposição" (DELEUZE, 1982, p. 20). Ao contrário das outras proposiçóes, o sentido seria irredutível a imagens particulares, desejos e crenças, e conceitos universais e gerais. É neutro, indiferente tanto ao particular quanto ao geral. Deleuze apresenta Husserl para explicar o sentido como o expresso: ele náo existe fora de sua expressão. Náo se trata de um círculo, como na proposição, mas de duas faces: uma voltada para as coisas e outra para as proposiçôes. É entre o estado de coisas que a proposiçáo designa e a proposição que o exprime, que o sentido se encontra. Assim, segundo Deleuze, o sentido é o próprio acontecimento. Dessa maneira, o acontecimento pode ser 
visualizado pela linguagem, pois é lá que ele se dá, onde o sentido expresso nos mostra suas dimensôes de efetuação sobre o texto.

O sentido da morte de Isabella não pode ser encontrado só nas capas e reportagens de Veja. Não pode ser materializado, dá-se em uma relação que escapa aos objetos específicos, fundando-se como momento constituir que dá a ver o acontecimento. Mas sua expressão pode ser visualizada na linguagem da revista, uma vez que esta se encontra em meio à reverberaçáo que se dá em busca de sentido. Veja tem suas duas faces voltadas ao mesmo tempo para o estado de coisas (que é constantemente modificado pelas reverberaçóes do acontecimento) e para a proposição (onde busca dar significaçáo ao estado de coisas). Trata-se de uma fronteira que, ao buscar o sentido, dá a ver o acontecimento em si, e seu poder de afetação e modificação.

Percebemos a existência de um movimento de significações fundado na linguagem que, por mais que se afaste do acontecimento inicial - acontecimento bruto -, busca sempre provocar o sentido. Durante as semanas que se seguiram à morte de menina Isabella, viu-se um excesso de mediação do acontecimento: telejornais, jornais impressos, revistas, transmissóes de rádio, sites na internet, conversas do dia a dia. $\mathrm{O}$ acontecimento repercutiu de tal maneira que, no final de abril, uma pesquisa CNT/Sensus apontou que 98,2\% dos brasileiros têm conhecimento do assassinato. Trata-se de um recorde, tornando-o o crime mais conhecido dos brasileiros.

No dia 18 de abril de 2008, Alexandre Nardoni e Ana Carolina Jatobá foram levados à $9^{\text {a }}$ Delegacia de Polícia de São Paulo. No mesmo dia, Isabella completaria seis anos de idade. O depoimento do casal levou a seu indiciamento por homicídio, mas o que talvez mais tenha chamado a atenção, foi a multidão em frente à DP. Entre as cerca de 200 pessoas que se aglomeraram estava Jefferson da Rocha, morador de Cuiabá, que dirigiu por doze horas até São Paulo para estar ali com os outros anônimos. Havia gente com bolo cantando parabéns para Isabella, gente fantasiada de anjo e até de Bin Laden ${ }^{3}$. Aquelas pessoas estariam lá por que motivo? De que maneira foram interpeladas para se aglomerarem em protesto e homenagem para uma criança que até algumas semanas atrás nunca tinham ouvido falar? O paradoxal do acontecimento obriga uma produção de sentido, de qualquer sentido. De alguma maneira aquelas pessoas pareciam buscar sua própria significação para o caso. Como em uma tentativa de recuperar sua experiência fragmentada pelo acontecimento, aquela platéia buscava algum sentido por representaçóes (anjos, Bin Laden, bolo de aniversário) ou pelo sentimento de pertencimento a um grupo.

O caso Isabella dá a ver a propagaçáo do acontecimento e os modos operatórios do sujeito fazer sua contra-efetuação: através de suas experiências anteriores, seja por uma busca de causalidade ou por outras referências. Durante esse movimento de propagação, onde a mídia é mediadora fundamental, os sujeitos buscam diminuir o caráter paradoxal do acontecimento pela contra-efetuação; através de suas experiências fragmentadas é que produzem sentido e tomam o acontecimento para si. O campo de investigaçáo do acontecimento é distribuído. Os sujeitos fazem uso de referências múltiplas através daquilo que Quéré chama de transação: 
O acontecimento entra, portanto, na experiência, não somente como fato, mas ainda como termo de uma transação. O acontecimento e aquele a quem ele acontece são, ambos, coisas que 'se tornam' no quadro de uma transação, embora o seu 'tornar' seja muito diferente. Uma pessoa não se limita a suportar um acontecimento: responde-lhe, salvo quando prevalece o suportar - ela pode então ser submersa pelo que the acontece, embrutecida ou siderada. (QUÉRÉ, 2005, p. 15).

O caso Isabella permitiu uma proposição coletiva, onde a mídia oferecia a designação, e a partir dela, os sujeitos trabalhavam a manifestação e significação do acontecimento. A ausência de um culpado claro - devido à principal suspeita recair sobre o pai, o que foge ao bom senso - acabou por criar uma busca de sentido coletiva, onde cada sujeito interpelado analisava as informaçôes enunciadas pela mídia, e buscava o fechamento de sentido, que saía fragmentado, confuso, contraditório. Criaram-se camadas de linguagem que se completavam, voltadas para essa proposição, preenchendo os vazios deixados e dando continuidade às reverberaçôes das ondas provocadas. Ao mesmo tempo buscava reorganizar o estado de coisas abalado pelo acontecimento.

Foram produzidas e divulgadas repetidamente simulaçôes do crime por computador (nas tvs), infográficos e pequenas histórias em quadrinhos (nas revistas e jornais); simulaçôes baseadas em outras simulaçóes - passando e transpassando da perícia às artes e vice-versa - provocando um excesso de significantes em busca de um significado único: o sentido do acontecimento. À medida que o acontecimento avança em significantes, a linguagem busca o início do significado.

No dia 23 de abril de 2008, cinco dias após o depoimento do pai e da madrasta da Isabella, a revista Veja fechou o sentido do acontecimento, destacando, em uma capa escura os olhos do casal Nardoni. Resolveu, assim, o paradoxo do acontecimento: "FORAM ELES".

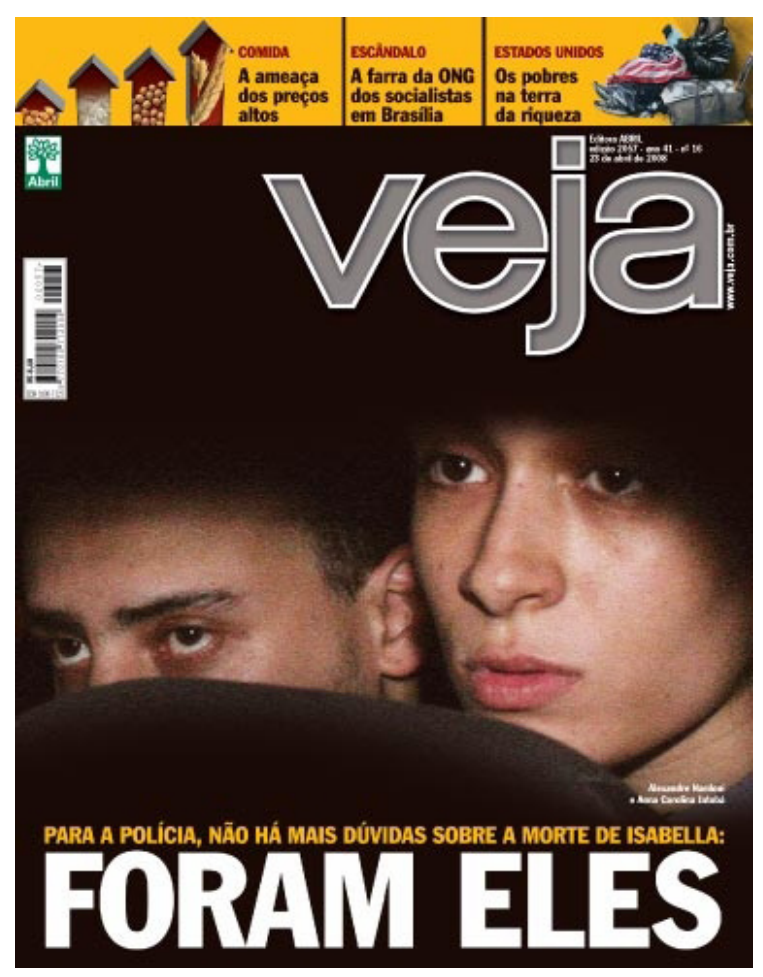


A reportagem vai, entáo, organizar o sentido em torno de uma intriga, apontando causas que levaram às conseqüências do acontecido. Intitulada "FRIOS E DISSIMULADOS" a matéria já traz o sentido na própria designação: não mais monstros ou uma maldade geral, mas Alexandre Nardoni e Anna Carolina Jatobá como causa da morte da criança. "Pai e madrasta mataram Isabella, numa seqüência de agressôes que começou ainda no carro, conclui a polícia”: a frase do subtítulo da reportagem já apresenta a ordenação que vai tirar do acontecimento seu caráter paradoxal, tornando-o fato localizado no tempo e no espaço. A força conclusiva do texto é completada pela arte que ocupa as duas primeiras páginas da matéria.

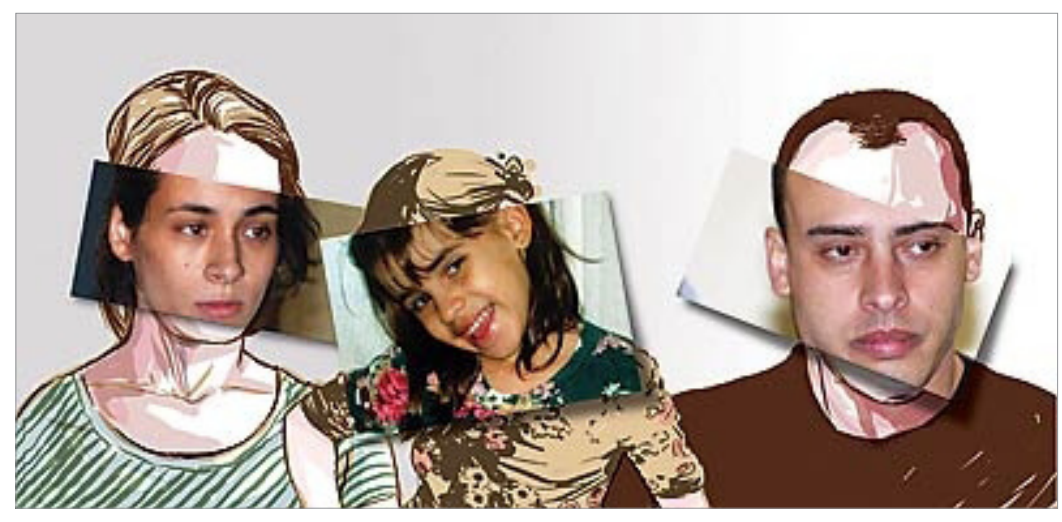

Os personagens do crime simulado, representados até então por assassinos sem rosto, agora possuem identidade. Sobre os desenhos, representação visual do imaginado, são coladas as fotografias, representações visuais dos personagens reais Anna Carolina, Isabella e Alexandre. A arte (colagem fotossobre-desenhos) fecha o sentido pela linguagem e completa a significação total do acontecimento.

$\mathrm{O}$ acontecimento se encaminha para um desenlace de sua forma em intriga ${ }^{4}$, esclarecendo o contexto de seu conjunto, revelando o estado de coisas existente e retomando os processos em curso. $\mathrm{O}$ inquérito que se coloca sobre o campo problemático criado pelo acontecimento em sua contribuição para a progressão da intriga torna-se parte fundamental de sua significação.

Tal como se integram nas intrigas, contribuindo para seu desenvolvimento, os
acontecimentos ganham um lugar em campos problemáticos e servem, pelo seu poder de
esclarecimento e de discriminação, de pivots dos inquéritos que procuram e elaboram
soluçôes. Ou, para retomar uma definição de G. Deleuze (1969, p. 72) que evoca
as consideraçôes de Dewey..., os acontecimentos 'sáo singularidades que se desdobram
num campo problemático, e na vizinhança das quais se organizam soluçóes (QUÉRÉ,
2005, p. 21).

Nisso que Quéré chamou de intriga do acontecimento, as reverberaçôes para o passado e futuro ganham sentido ao se apresentarem em uma ordem causal, que a revista apresenta por uma retranca chamada "O crime passo a passo". Aqui, o acontecimento perde todo seu poder de modificação, pois finalmente se encontra enquadrado, explicado, organizado dentro do esperado. 

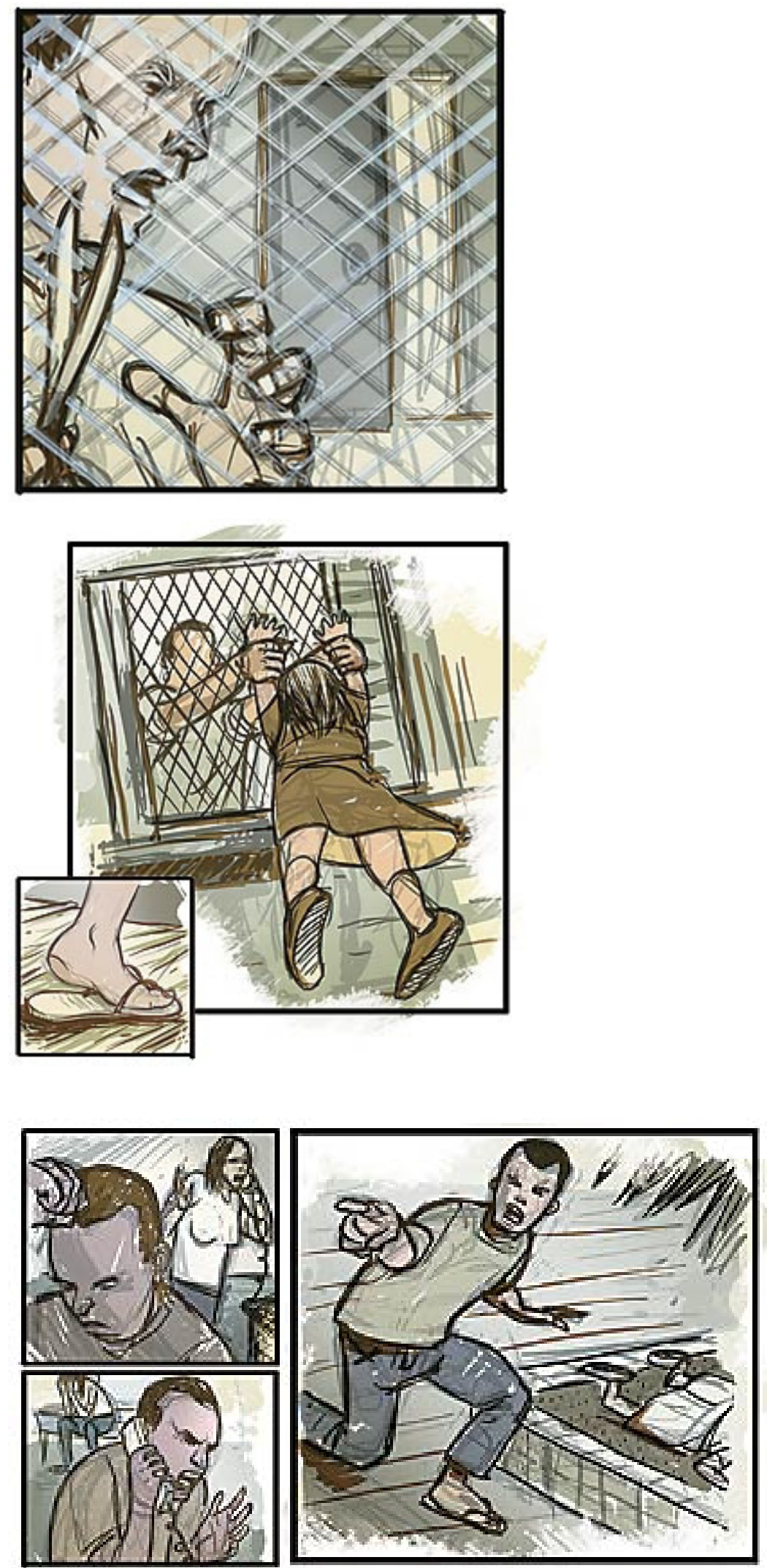

O crime é didaticamente explicado por uma série de desenhos e textos em uma reconstituição da intriga, desde a festa em que a família se encontrava até a chegada da polícia ao local do crime. O sentido já é dado, e a significaçáo se apresenta na designação, pois os assassinos se assemelham fisicamente aos 
personagens reais. Não há mais um acontecimento que reverbera sem permitir a expressão de sentido pela revista. O crime aparece ligado ao estado de coisas, como conseqüência de uma série de causas detalhadamente explicadas. $\mathrm{O}$ texto da matéria se volta para o passado dos envolvidos, construindo uma intriga em que o pai de Isabella é apresentado desde o início como incompetente e violento. À medida que o acontecimento se afasta de seu início, aproxima-se cada vez mais de seu sentido original. Numa das ediçóes (O/MAL) nota-se o movimento de Veja em atravessar o espelho, pois assim como Alice, é pelo afastamento que se busca a aproximação. As generalizaçôes acerca do mal, fogem do acontecido, mas buscam dar algum significado a ele. Na outra edição (FORAM ELES), o espelho é quebrado e em seus fragmentos refletem-se os culpados: "O 'monstro' que matou a menina Isabella e que seu pai, Alexandre Nardoni, em carta divulgada à imprensa, prometeu não sossegar até encontrar estava, afinal, diante do espelho. E a mulher, que também em carta afirmou ser a criança 'tudo' na sua vida, ajudou a matá-la com as próprias mãos”. O sentido está dado. $\mathrm{O}$ acontecimento Isabella, encerrado. $\mathrm{O}$ leitor de Veja pode concluir que este é um fato. Fim e início se encontram fechando um círculo com sentido. Retornamos ao espelho do qual nos afastamos. "O mal", na verdade, "foram eles".

\section{Notas}

1 Trabalho apresentado VI SBPJor - Encontro Nacional de Pesquisadores em Jornalismo, novembro de 2008.

2 Patrick Charaudeau (2003) chama de acontecimento bruto aquilo que produz uma modificação no estado do mundo, se manifestando fisicamente, porém sem significação. Para que signifique, é necessário que seja percebido, mas também que seja formulado a respeito dele um discurso que permita dotá-lo de sentido e integrá-lo a um mundo de inteligibilidade social.

3 Informaçóes retiradas do Jornal Folha de S. Paulo de 19 de abril de 2008.

${ }^{4}$ Segundo Quéré (2005), a intriga não quer necessariamente dizer narrativa, podendo assumir diferentes formas a partir de um inquérito sobre determinada situação. 


\section{Referências bibliográficas}

BENNETI, Márcia. "A ironia como estratégia discursiva da revista Veja". In: Anais do XVI Encontro Anual da Associação Nacional dos Programas de Pós-Graduação em Comunicação. Curitiba: Compôs, 2007. v. 1.

CARDOSO, Carla Rodrigues. Nos bastidores do óbvio: A capa de Newsmagazine como Dispositivo de Comunicação. Anais do $V$ Congresso da Associação Portuguesa de Ciências da Comunicação. Minho: Universidade de Minho, 2007.

CARROL, Lewis. As aventuras de Alice no País das Maravilhas. São Paulo: Martins Fontes, 2002.

CHAURAUDEAU, Patrick. El discurso de la informacion. Barcelona: Gedisa, 2003.

DELEUZE, Gilles. Lógica do sentido. São Paulo: Perspectiva, 1982.

MOUILLAUD, Maurice. O Jornal da forma ao sentido. Brasília: Paralelo 15, 1997.

NORA, Pierre. História: novos problemas. Rio de Janeiro: Livraria Francisco Alves Editora, 1979.

QUÉRÉ, Louis. Entre facto e sentido: a dualidade do acontecimento. Trajectos n. 6. Lisboa: Lisboa, 2005.

SCALZO, Marília. Jornalismo de revista. São Paulo: Contexto, 2004.

Veja: edição 2055, ano 41, n.14, de 9/4/2008 e edição 2057, ano 41, n.16, 23/4/2008. 